\title{
Abnormal Synaptic Plasticity in the Striatum of Mice Lacking Dopamine D2 Receptors
}

\author{
Paolo Calabresi, ${ }^{1}$ Adolfo Saiardi, ${ }^{3}$ Antonio Pisani, ${ }^{1}$ Ja-Hyun Baik, ${ }^{3}$ Diego Centonze, ${ }^{1}$ Nicola B. Mercuri, ${ }^{1,2}$ \\ Giorgio Bernardi, ${ }^{1,2}$ and Emiliana Borrelli ${ }^{3}$ \\ ${ }^{1}$ Clinica Neurologica, Universitá di Roma Tor Vergata, Dipartimento Sanitá, 00173 Rome, Italy, ${ }^{2}$ Ospedale S. Lucia, Via \\ Ardeatina, Rome, Italy, and ${ }^{3}$ Institut de Génétique et de Biologie Moléculaire et Cellulaire, Centre National de la \\ Recherche Scientifique/Institut National de la Santé et de la Recherche Médicale/Université Louis Pasteur, 67404 Illkirch \\ Cedex, Strasbourg, France
}

Dopamine D2 receptors (D2Rs) are of crucial importance in the striatal processing of motor information received from the cortex. Disruption of the D2R gene function in mice results in a severe locomotor impairment. This phenotype has analogies with Parkinson's disease symptoms. D2R-null mice were used to investigate the role of this receptor in the generation of striatal synaptic plasticity. Tetanic stimulation of corticostriatal fibers produced long-term depression (LTD) of EPSPs in slices from wild-type (WT) mice. Strikingly, recordings from D2R-null mice showed the converse: long-term potentiation (LTP). This LTP, unlike LTD, was blocked by an NMDA receptor antagonist. In magnesium-free medium, LTP was also revealed in WT mice and found to be enhanced by L-sulpiride, a D2R antagonist, whereas it was reversed into LTD by LY 17555, a D2R agonist. In D2R-null mice this modulation was lost. Thus, our study indicates that D2Rs play a key role in mechanisms underlying the direction of long-term changes in synaptic efficacy in the striatum. It also shows that an imbalance between D2R and NMDA receptor activity induces altered synaptic plasticity at corticostriatal synapses. This abnormal synaptic plasticity might cause the movement disorders observed in Parkinson's disease.

Key words: LTD; LTP; synaptic plasticity; striatum; dopamine; NMDA; dopamine D2 receptor; D2 receptor knock-out mice
Dopamine receptors play a pivotal role in the pathophysiology and treatment of Parkinson's disease and schizophrenia (Albin et al., 1989; Starr, 1995). Among the different dopaminergic pathways arising in the substantia nigra and ventral tegmental area, the nigrostriatal projection plays a crucial role in sensorimotor coordination and initiation of movements (Albin et al., 1989; Alexander et al., 1990).

Dopamine D1 receptors (D1Rs) and D2Rs account for the vast majority of dopamine receptors in the striatum (Gingrich and Caron, 1993). Interestingly, although D1R-deficient mice exhibit normal coordination and mild hyperlocomotion (Drago et al., 1994; Xu et al., 1994), D2R-deficient mice present a phenotype that strikingly resembles the extrapyramidal symptoms of Parkinson's disease (Baik et al., 1995).

The striatum also receives extensive glutamatergic projections from the cerebral cortex (Alexander and Crutcher, 1990; Alexander et al., 1990). Morphological studies have shown a close association between glutamatergic and dopaminergic inputs (Smith and Bolam, 1990; Seasack et al., 1994). A functional link has been postulated between dopamine and excitatory amino

\footnotetext{
Received Jan. 8, 1997; revised March 25, 1997; accepted March 28, 1997.

A.S. was supported by the Association pour la Recherche sur le Cancer and Fondation pour la Recherche Medicale, and J.-H.B. was supported by the Fyssen Foundation. This work was supported by the Italian Consiglio Nazionale delle Ricerche and grants to P.C. and G.B. and by grants from the Institut National de la Santé et de la Recherche Médicale, Centre National de la Recherche Scientifique, Centre Hospitelier Universitaire Regionale, and Association pour la Recherche contre le Cancer to E.B. We thank G. Gattoni, M. Tolu, and M. Federici for their excellent technical assistance.

Correspondence should be addressed to E. Borrelli, Institut de Génétique et de Biologie Moléculaire et Cellulaire, BP163, 67404 Illkirch Cedex, Strasbourg, France.

Dr. Baik's present address: Clinical Medicine Research Institute, College of Medicine, Yonsei University, CPO Box 8044, Seoul 120-752, South Korea.

Copyright (C) 1997 Society for Neuroscience $0270-6474 / 97 / 174536-09 \$ 05.00 / 0$
}

acids in the striatum on the basis of behavioral studies performed on animal models of Parkinson's disease (Starr, 1995). In dopamine-depleted animals, glutamate receptor antagonists reverse akinesia and facilitate locomotion (Starr, 1995). Furthermore, high-frequency stimulation of corticostriatal glutamatergic fibers induces a long-term depression (LTD) of EPSPs recorded from striatal spiny neurons (Calabresi et al., 1992a; Lovinger et al., 1993; Walsh, 1993). This phenomenon might represent a cellular substrate for motor learning (Calabresi et al., 1996a). Although NMDA receptors are not involved in striatal LTD, a rise in intracellular calcium in the postsynaptic neuron seems to be the initial step for the induction of this phenomenon. Accordingly, striatal LTD is blocked either by intracellular application of calcium chelators (Calabresi et al., 1994, 1996b) or by chronic lithium treatment (Calabresi et al., 1993b).

Moreover, striatal LTD shares several characteristics with other forms of synaptic plasticity in the brain (Ito, 1989; Linden and Connor, 1995; Artola et al., 1996), but the involvement of two transmitter systems (glutamate and dopamine) seems to be a unique feature of this event (Calabresi et al., 1996a). Striatal LTD is blocked either by lesioning the nigrostriatal pathway or by pretreatment with either D1R or D2R antagonists (Calabresi et al., 1992a). These manipulations, however, suffer from a relative lack of pharmacological specificity. Nigral lesions affect all the different dopaminergic receptors and also alter other neurotransmitter systems; in addition, dopamine receptor antagonists cannot discriminate among subtypes of the D1R and D2R subfamilies. Thus, D2R-deficient mice provide an unprecedented opportunity to evaluate, in a more selective manner, the roles of this receptor in dopamine-mediated neuronal function. Using these mice, we have investigated the functional interaction between glutamater- 
gic inputs and dopamine receptors in spiny striatal neurons by electrophysiological methods. Here we demonstrate that the D2R plays an essential role in the formation of striatal LTD and exerts a negative control in the expression of an NMDA-mediated longterm potentiation (LTP) at corticostriatal synapses.

\section{MATERIALS AND METHODS}

Animals were bred under standard animal housing conditions, in a $12 \mathrm{hr}$ light/dark cycle. Food and water were available ad libitum. All experiments were conducted in conformity with the European Communities Council Directive of November 1986 (86/609/EEC).

The generation of D2R-null mice has been reported previously (Baik et al., 1995). The knock-out and wild-type (WT) animals used in these experiments were obtained from the mating of heterozygous D2R-null mice. Experiments were performed blindly (without knowledge of the genotype of the slice). Corticostriatal slices were prepared as described previously (Calabresi et al., 1990, 1992a,b, 1993a,b, 1994). Briefly, coronal sections (200-300 $\mu \mathrm{m})$ were obtained using a vibratome; those including the neostriatum and the neocortex were used. A single slice was transferred to a recording chamber $(0.5 \mathrm{ml}$ volume $)$ and submerged in a continuously flowing Krebs solution (126 mM NaCl, $2.5 \mathrm{~mm} \mathrm{KCl}, 1.2 \mathrm{~mm}$ $\mathrm{NaH}_{2} \mathrm{PO}_{4}, 1.2 \mathrm{mM} \mathrm{MgCl} 2,2.4 \mathrm{mM} \mathrm{CaCl}, 11 \mathrm{mM}$ glucose, $25 \mathrm{~mm}$ $\left.\mathrm{NaHCO}_{3}\right)\left(35^{\circ} \mathrm{C}, 2-3 \mathrm{ml} / \mathrm{min}\right)$ gassed with a $95 \% \mathrm{O}_{2} / 5 \% \mathrm{CO}_{2}$ mixture. In some experiments external magnesium was omitted. Intracellular recording electrodes were filled with $2 \mathrm{M} \mathrm{KCl}(30-60 \mathrm{mOhm})$, and extracellular electrodes were filled with $2 \mathrm{M} \mathrm{NaCl}(5-10 \mathrm{mOhm})$. Signals were recorded with the use of an Axoclamp 2-A amplifier, displayed on an oscilloscope, and stored in a digital system. For synaptic stimulation, bipolar electrodes were used. The stimulating electrode was located either in the cortical areas close to the recording electrode $(0.5-3.0 \mathrm{~mm})$ or in the white matter between the cortex and the striatum. As conditioning tetanus, we used three trains ( $3 \mathrm{sec}$ duration, $100 \mathrm{~Hz}$ frequency, at $20 \mathrm{sec}$ intervals). The duration of each individual pulse was $0.01-0.3 \mathrm{msec}$, and the intensity was 3-10 V. Under control condition, the frequency of stimulation was 0.1-0.05 Hz. During tetanic stimulation, the intensity was increased to generate a single action potential during the EPSP in the intracellular experiments and to levels producing the maximal field potential in the extracellular experiments (approximately twice the test intensity). The field potential amplitude was defined as the average of the amplitude from the peak of the early positivity to the peak negativity, and the amplitude from peak negativity to peak late positivity. Quantitative data on post-tetanic modifications are expressed as a percentage of the controls, the latter representing the mean of responses recorded during a stable period (15-30 min) before tetanic stimulation. Values given in the text and in the figures are mean \pm SEM of changes in the respective cell populations. Student's $t$ test was used to compare the means.

DL-2-amino-5-phosphovaleric acid (APV) and 6-cyano-7-nitroquinoxaline-2,3-dione (CNQX) were purchased from Tocris, L-sulpiride from Ravizza, LY17555 from RBI (Natick, MA), and SCH 23390 from Schering-Plough. All other reagents were purchased from Sigma (St. Louis, MO).

\section{RESULTS}

\section{Electrophysiological properties of striatal neurons in WT and D2R-null mice}

Electrophysiological experiments were conducted on corticostriatal slices obtained from homozygous D2R-deficient and WT mice. Intracellular recordings showed that intrinsic membrane properties of striatal neurons were similar in the two groups and closely resembled the electrical activity described previously for rat striatal spiny neurons (Kita et al., 1984; Calabresi et al., 1990, 1993a,b; Jiang and North, 1991). Indeed, the average resting membrane potential was $-86 \pm 3 \mathrm{mV}(n=53)$ in D2R-null mice and $-85 \pm 3 \mathrm{mV}(n=55)$ in WT animals. In both groups neurons were silent at rest. The injection of positive current (0.5-1.0 nA) through the recording pipette induced a tonic firing discharge (Fig. $1 A$ ) in both groups.

Voltage-clamped neurons, at membrane potentials close to the resting level $(-85 \mathrm{mV})$, from D2R-deficient and WT mice displayed similar responses to voltage steps $(0.5-3.0 \mathrm{sec}$ duration) of increasing amplitude, shifting the membrane in depolarizing and hyperpolarizing directions (from -115 to $-55 \mathrm{mV}$ ) (Fig. 1A). Membrane rectification was present in both groups (Kita et al., 1984; Calabresi et al., 1990, 1993a,b; Jiang and North, 1991). The corticostriatal transmission in D2R-null and WT mice has pharmacological characteristics similar to those in rat. In both systems, AMPA glutamate receptors mediate the cortically evoked EPSPs (Cherubini et al., 1988; Jiang and North, 1991; Calabresi et al., 1992b, 1996a). Indeed, in both animal groups, the subthreshold EPSPs that were recorded (intracellularly recorded after a single cortical activation) were not affected by $50 \mu \mathrm{M}$ APV, an NMDA glutamate receptor antagonist (Fig. $1 B, a, b)$. Conversely, EPSPs were almost completely abolished by coadministration of $50 \mu \mathrm{M}$ APV plus $10 \mu \mathrm{M}$ CNQX, an AMPA glutamate receptor antagonist (Fig. $1 B, a, b)$ (WT, $n=6$; D2R-null, $n=6$ ). In the absence of external magnesium, the EPSP amplitude increased, unmasking an APV-sensitive component that was similar in both WT and D2R-null mice. Indeed, under this condition the coadministration of APV plus CNQX was required to block the EPSP (Fig. $1 B, c, d$ ) (WT, $n=6$; D2R-null, $n=6$ ). In magnesium-free medium, the half-decay time of the EPSP increased similarly in both groups (control WT $=20 \pm 3 \mathrm{msec}, n=40$; control D2R-null $=20 \pm 4$ msec, $n=35$; magnesium-free WT $=42 \pm 4 \mathrm{msec}, n=26$; magnesium-free D2R-null $=41 \pm 4 \mathrm{msec}, n=28$ ).

\section{High-frequency stimulation in WT and D2R-null mice}

Strikingly, differences were observed between D2R-null mice and WT animals in response to tetanic activation of cortical fibers. Slices obtained from WT animals showed a significant LTD in most of the extracellular experiments (11 of 14) and in all the intracellular experiments $(n=11)$ (Fig. 2). In the remaining three recordings the tetanus did not cause a persistent depression of field potentials. Actually, in one case a transient depression (10 min) was observed, whereas in the two other experiments a small LTP $(+14$ and $+16 \%)$ was observed. These results are consistent with previous observations: repetitive activation of cortical fibers induces LTD at corticostriatal synapses (Calabresi et al., 1992a, 1993b, 1996a; Lovinger et al., 1993; Walsh, 1993). In contrast, tetanic stimulation of striatal slices from D2R-null mice produced LTP of corticostriatal synaptic transmission in all of the extracellular experiments $(n=12)$, as well as in the intracellular recordings $(n=9)$ (Fig. 2). LTP observed in D2R-null mice and LTD recorded from WT animals were not coupled with significant changes of the postsynaptic membrane properties of the recorded neurons.

We have measured the amplitude, the half-decay time, and the duration of the membrane depolarizations induced by tetanic stimulation in WT and D2R-null mice to investigate whether differential characteristics of these events could explain the different forms of synaptic plasticity observed in the two groups. These parameters did not significantly differ in the two classes of animals. The amplitude was $39 \pm 5 \mathrm{mV}(n=11)$ in WT animals and $38 \pm 5 \mathrm{mV}(n=9)$ in D2R-null mice $(p>0.05)$. The half-decay time was $3 \pm 0.3 \mathrm{sec}(n=11)$ in WT mice and $2.9 \pm$ $0.4 \mathrm{sec}(n=9)$ in D2R-null animals $(p>0.05)$. The duration was $7.9 \pm 2 \sec (n=11)$ in WT mice and $8 \pm 3 \sec (n=9)$ in D2R-null animals $(p>0.05)$.

\section{APV on synaptic plasticity in WT and D2R-null mice}

Two forms of LTP have been described in the hippocampus, the first dependent on and the second independent of NMDA receptor activation (for reviews, see Bliss and Collingridge, 1993; Nicoll 

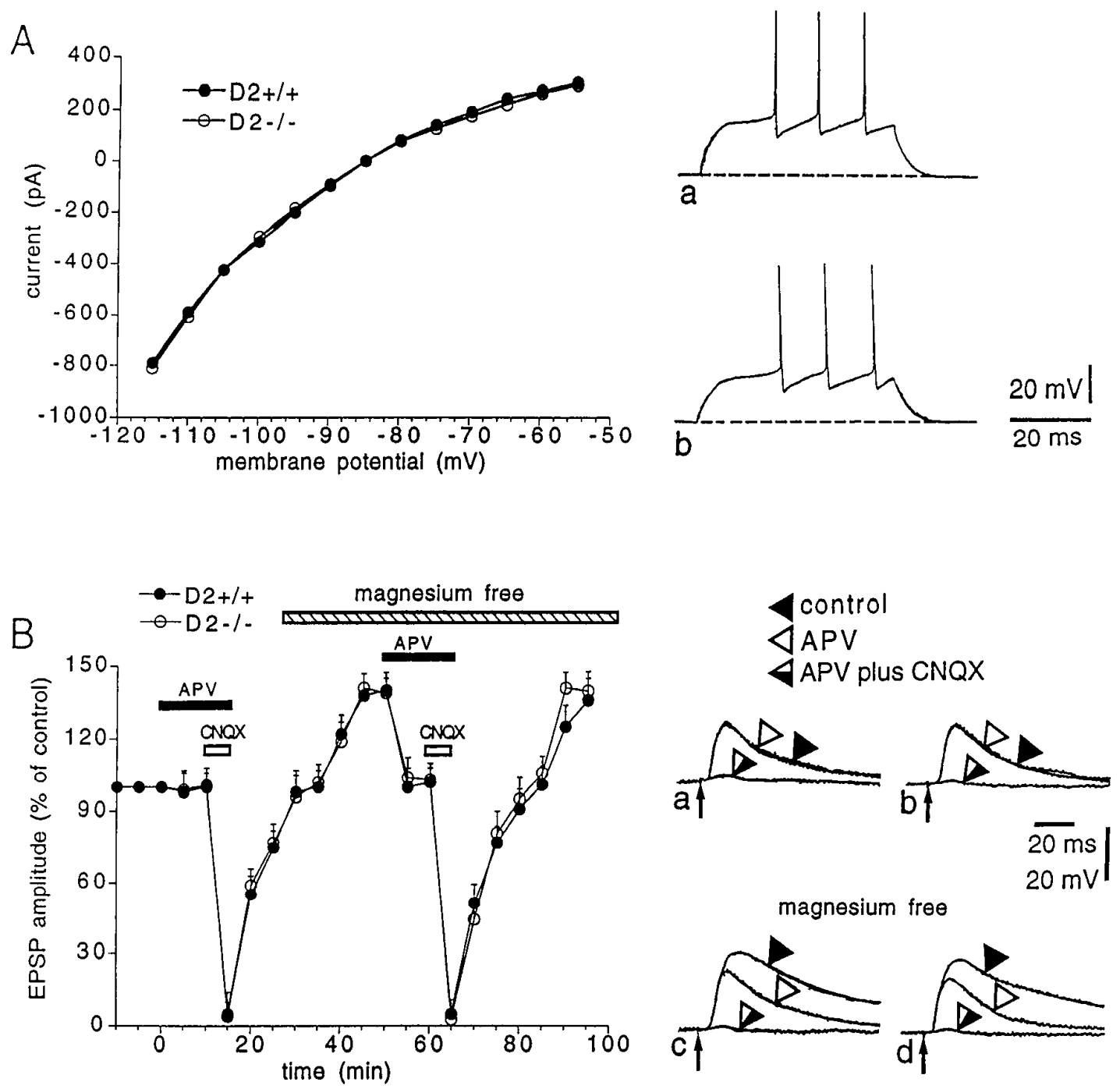

Figure 1. In vitro intrinsic membrane properties of striatal neurons and pharmacological characteristics of corticostriatal synaptic potentials are similar for both WT $(\mathrm{D} 2+/+)$ and D2R-null mice $(\mathrm{D} 2-/-)$. $A$, The graph shows the current-voltage relationship obtained from two striatal neurons recorded from a WT ( filled circles) or a D2R-null mouse (open circles). Plots were obtained from voltage-clamp experiments, holding the cells at $-85 \mathrm{mV}$ and applying positive and negative steps (0.5-3.0 sec duration). Right, Injection of a positive current pulse (0.9 nA) evoked a tonic firing discharge in neurons recorded from either a WT $(a)$ or a D2R-null animal $(b)$. In both experiments the resting membrane potential (RMP; dotted line) was $-85 \mathrm{mV}$. $B$, The graph shows the pharmacology of the cortically evoked EPSPs recorded in WT ( filled circles; $n=6$ ) or in D2R-null mice (open circles; $n=6$ ), either in control medium or in the absence of external magnesium. Bars indicate the time of application of APV $(50 \mu \mathrm{M})$, CNQX $(10 \mu \mathrm{M})$, and magnesium-free medium. Right, EPSPs recorded from single experiments in WT $(a, c)$ or in D2R-deficient $(b, d)$ slices, in the presence $(a, b)$ or absence $(c, d)$ of external magnesium. Note that APV $(50 \mu \mathrm{M})$ reduced the EPSPs only in magnesium-free medium. RMPs were $-85 \mathrm{mV}(a)$ and $-85 \mathrm{mV}(b)$. In this figure and in the following ones arrows indicate the artifact of the single synaptic stimulation.

and Malenka, 1995). The first is observed in the CA1 region of the hippocampus and the second at mossy fiber synapses. To investigate whether striatal LTP recorded from D2R-null mice required activation of NMDA receptors, we preincubated the slices in 50 $\mu \mathrm{M}$ APV $10 \mathrm{~min}$ before tetanic stimulation.

Although in physiological concentrations of magnesium this NMDA receptor antagonist did not affect the EPSP amplitude evoked by a single stimulation recorded from D2R-null mice (Fig. $1 B)$, it reversibly prevented the formation of LTP in both extracellular (Fig. $3 A)(n=13)$ and intracellular experiments $(n=4$; data not shown). In contrast, LTD observed in WT mice was not affected by APV (Fig. $3 A)(n=9)$. This finding is in agreement with previous observations showing that striatal LTD is not dependent on NMDA glutamate receptors (Calabresi et al., 1992a, 1996a; Lovinger et al., 1993; Walsh, 1993).

\section{Postsynaptic responses to NMDA in WT and D2R-null mice}

We also investigated whether the absence of D2Rs in mutant mice might affect the response to exogenously applied NMDA. Similar dose-response curves to NMDA application were observed in both groups (Fig. $3 B$ ) (WT, $n=5$; D2R-null, $n=6$ ), suggesting that the postsynaptic sensitivity to NMDA is not altered in D2Rnull mice.

\section{Repetitive low-frequency stimulation in WT and D2R-null mice}

An NMDA-dependent LTD induced by repetitive low frequency stimulation has been described in the area CA1 of the hippocampus (Mulkey and Malenka, 1992; Malenka, 1994). Given the involvement of NMDA receptors in LTP observed in slices from 
A

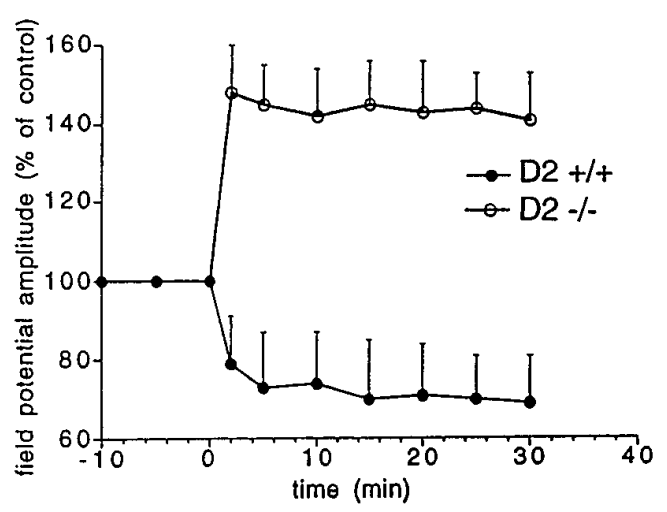

pre-tetanus $20 \mathrm{~min}$ post-tetanus
B

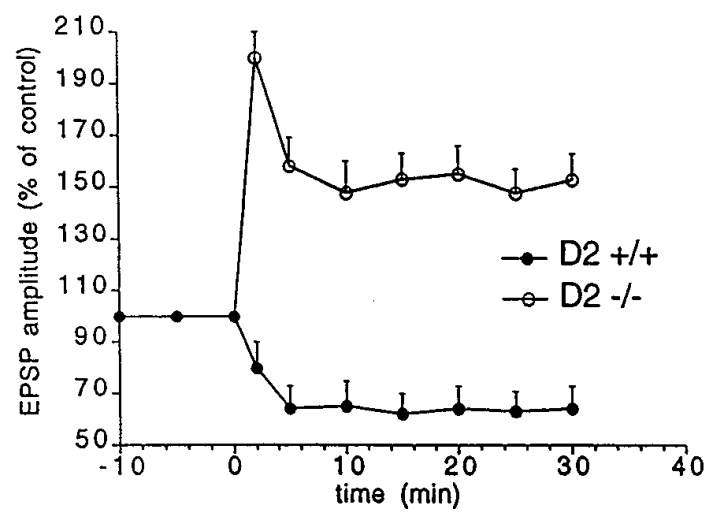

pre-tetanus

20 min post-tetanus

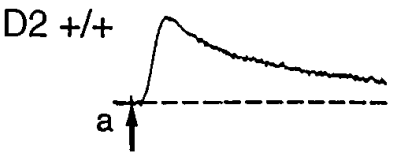

D2 -/-

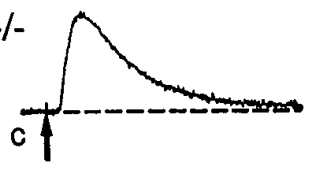

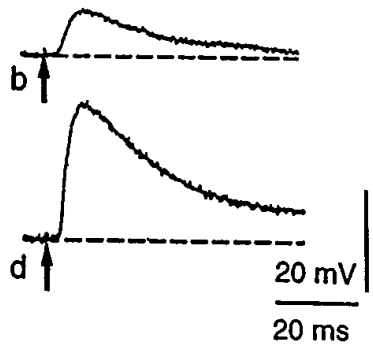

Figure 2. Tetanic stimulation of corticostriatal fibers induces LTD in slices obtained from WT mice but LTP in slices prepared from D2R-null mice. $A$, The graph summarizes the results from extracellular experiments, measuring the field potential amplitude, performed by using either WT ( filled circles; $n=11$ ) or D2R-null brain sections (open circles; $n=12$ ). In this figure and in the following ones the tetanus was delivered at time 0 . The bottom part of the figure shows traces from two single extracellular experiments performed with WT $(a, b)$ or D2R-null $(c, d)$ brain slices. $B$, The graph represents the results on the EPSP amplitude obtained from intracellular experiments (WT, $n=11$; D2R-null, $n=9$ ). Traces of EPSPs recorded before and after the tetanus from WT ( $a, b$ ) or $\mathrm{D} 2 \mathrm{R}$-null $(c, d)$ brain sections are represented in the bottom part of the figure. RMPs were $-84 \mathrm{mV}(a, b)$ and $-85 \mathrm{mV}(2 c, d)$.

D2R-null mice, we tested whether a low-frequency stimulation induced long-term changes in synaptic efficacy. Repetitive (15 min) low-frequency stimulation $(1 \mathrm{~Hz})$ caused only a transient (5-10 $\mathrm{min})$ depression of the intracellularly recorded EPSP amplitude in both WT $(-26 \pm 5 \% ; n=5)$ and D2R-null mice $(-27 \pm 6 \% ; n=5)$, but failed to determine long-term effects (data not shown). In WT mice even in the presence of either L-sulpiride ( $1 \mu \mathrm{M} ; n=4)$, a D2R antagonist, or LY 17555 (3 $\mu \mathrm{M}$; $n=4$ ), a D2R agonist, this stimulation protocol produced only a short-term depression of EPSP amplitude. In addition, these drugs affected neither the control EPSP nor the intrinsic membrane properties of the recorded neurons (data not shown).

\section{SCH 23390 on synaptic plasticity in WT and D2R-null mice}

D1Rs have also been involved in the formation of striatal LTD (Calabresi et al., 1992a, 1996a). Therefore, in some intracellular experiments we also tested the effect of $3 \mu \mathrm{M} \mathrm{SCH} 23390$, a D1R antagonist, on the induction of both LTD in WT mice and LTP in D2R-null mice. This antagonist blocked the formation of LTD in WT animals $(n=4)$, but it did not alter the LTP measured in D2R-null mice $(n=5)$, suggesting that D1Rs do not play a major role in LTP observed in mutant mice (Fig. $4 A$ ).

\section{L-sulpiride on synaptic plasticity in WT mice}

In the presence of $1 \mu \mathrm{M}$ L-sulpiride, tetanic stimulation failed to induce LTD in WT mice. Under this condition, a significant synaptic potentiation was observed immediately after the tetanus. This potentiation lasted only 10-20 min in both extracellular (Fig. 4B) $(n=5)$ and intracellular ( $n=10$; data not shown) recordings. After the washout of L-sulpiride, tetanic stimulation induced LTD (Fig. 4B) $(n=8)$. These findings indicate that the acute blockade of D2Rs prevents the generation of LTD but is not sufficient to cause striatal LTP.

\section{L-sulpiride and LY 17555 on LTP in a magnesium-free medium}

Interestingly, in magnesium-free medium, a condition that discloses an NMDA component of the EPSP, tetanic stimulation of corticostriatal fibers induces an APV-sensitive LTP in rats (Calabresi et al., 1992b). To further confirm the modulatory role of D2Rs on this NMDA-dependent LTP, we analyzed during intracellular experiments the synaptic plasticity in the absence of external magnesium. In slices obtained from WT mice, tetanic stimulation induced LTP (Fig. $5 A)(n=11)$, which was prevented by $50 \mu \mathrm{M}$ APV ( $n=4$; data not shown). This LTP was significantly $(p<0.001)$ increased by preincubation of the slices in $1 \mu \mathrm{M}$ 

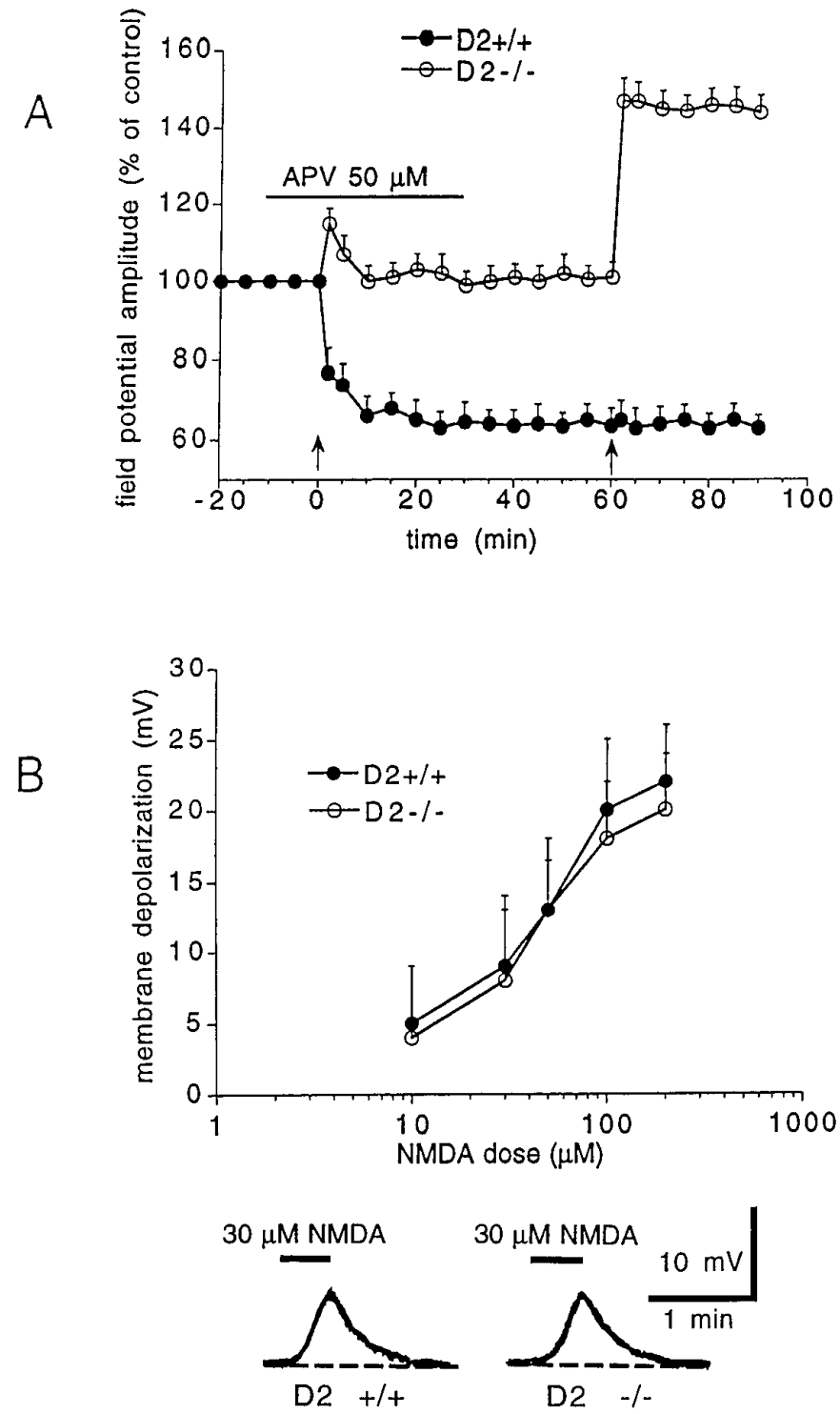

Figure 3. Effects of APV on synaptic plasticity and postsynaptic action of NMDA in neurons recorded from WT and D2R-null slices. $A$, APV (50 $\mu \mathrm{M})$ reversibly prevented the induction of LTP in D2R-null mice (open circles; $n=13$ ) but not the formation of LTD in WT animals ( filled circles; $n=9$ ). The bar shows the period of application of APV. Arrows indicate when the tetanic stimulation was delivered. $B$, The graph shows the dose-response curve for NMDA-induced membrane depolarization obtained from WT ( filled circles; $n=5$ ) and D2R-null (open circles; $n=6$ ) slices. NMDA was bath-applied $(20-30 \mathrm{sec})$ in the presence of $1 \mu \mathrm{M}$ tetrodotoxin. The bottom part of the figure shows membrane depolarizations obtained from a WT slice (left) and from a D2R-null slice (right) after bath application of NMDA. In both cases the RMP was $-85 \mathrm{mV}$.

L-sulpiride (Fig. $5 A)(n=7)$, whereas it was blocked by application of $3 \mu \mathrm{M}$ LY 17555. In the presence of this D2R agonist, an LTD was revealed (Fig. $5 A)(n=7)$. These findings indicate that in WT animals, activation of D2Rs normally exerts a negative control on the formation of the NMDA-dependent LTP. In D2Rnull mice, tetanic stimulation in the absence of magnesium produced an LTP that was significantly (Fig. $5 B)(n=10 ; p<0.001)$ larger than the one recorded from WT mice in the same experimental condition. LTP recorded from D2R-null mice in magnesium-free conditions closely resembled the potentiation observed in WT mice in the absence of magnesium and in the
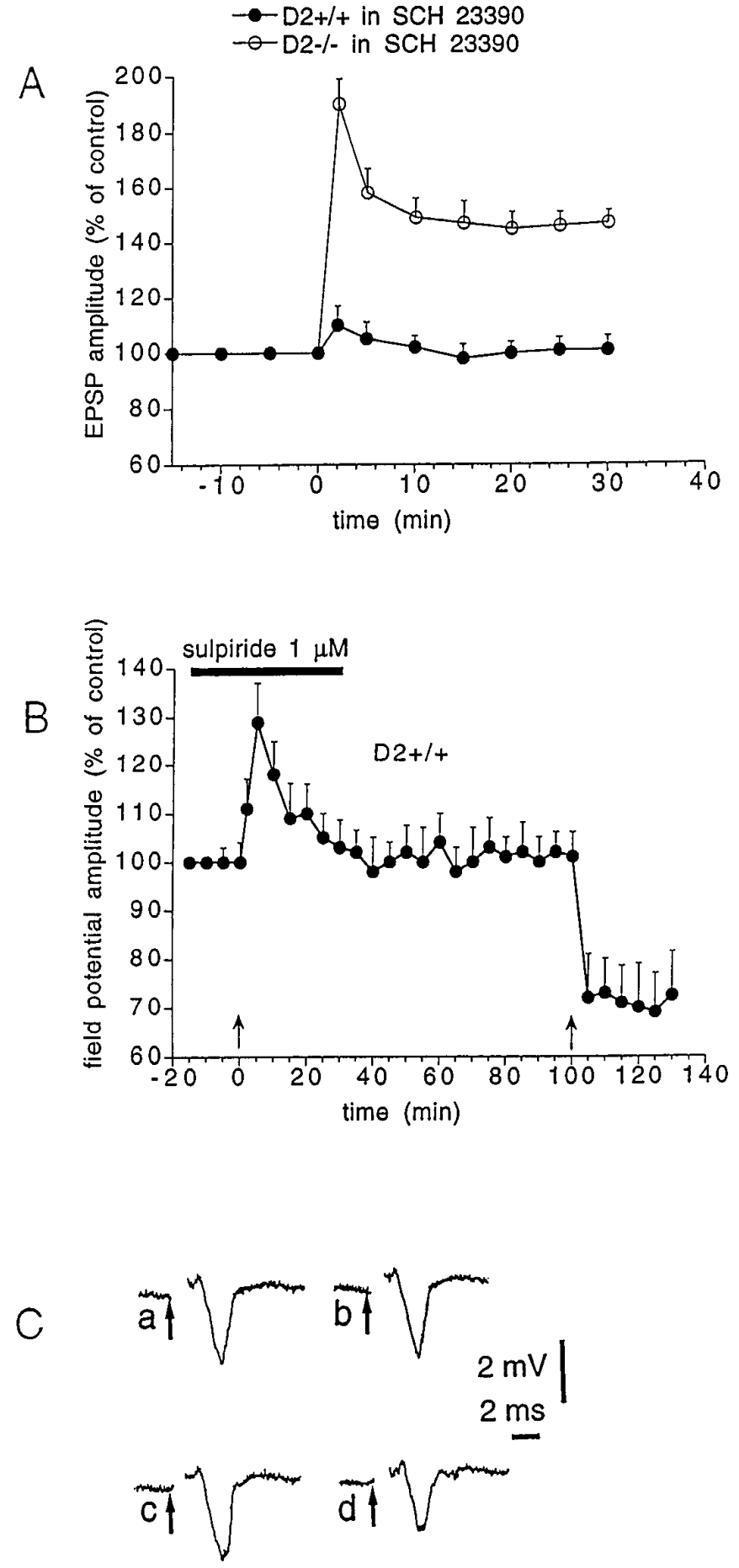

Figure 4. Effects of SCH 23390 and L-sulpiride on synaptic plasticity recorded in normal medium. $A$, Intracellular experiments show that the pretreatment of the slices with $3 \mu \mathrm{M} \mathrm{SCH} 23390$ prevented the formation of LTD in WT slices ( filled circles; $n=4$ ), but it did not affect LTP in D2R-null slices (open circles; $n=5$ ). $B$, Extracellular experiments from WT slices ( filled circles; $n=8$ ) show that acute blockade of D2Rs by $1 \mu \mathrm{M}$ L-sulpiride reversibly prevented the induction of LTD but failed to cause LTP. Arrows indicate when the tetanic stimulation was delivered. $C$, The traces represent field potentials recorded from WT slices before $(a)$ and 20 min after $(b)$ the tetanus in the presence of L-sulpiride. Traces in $c$ and $d$ show field potentials recorded after the washout of L-sulpiride, respectively, before and $20 \mathrm{~min}$ after the second tetanic stimulation. 

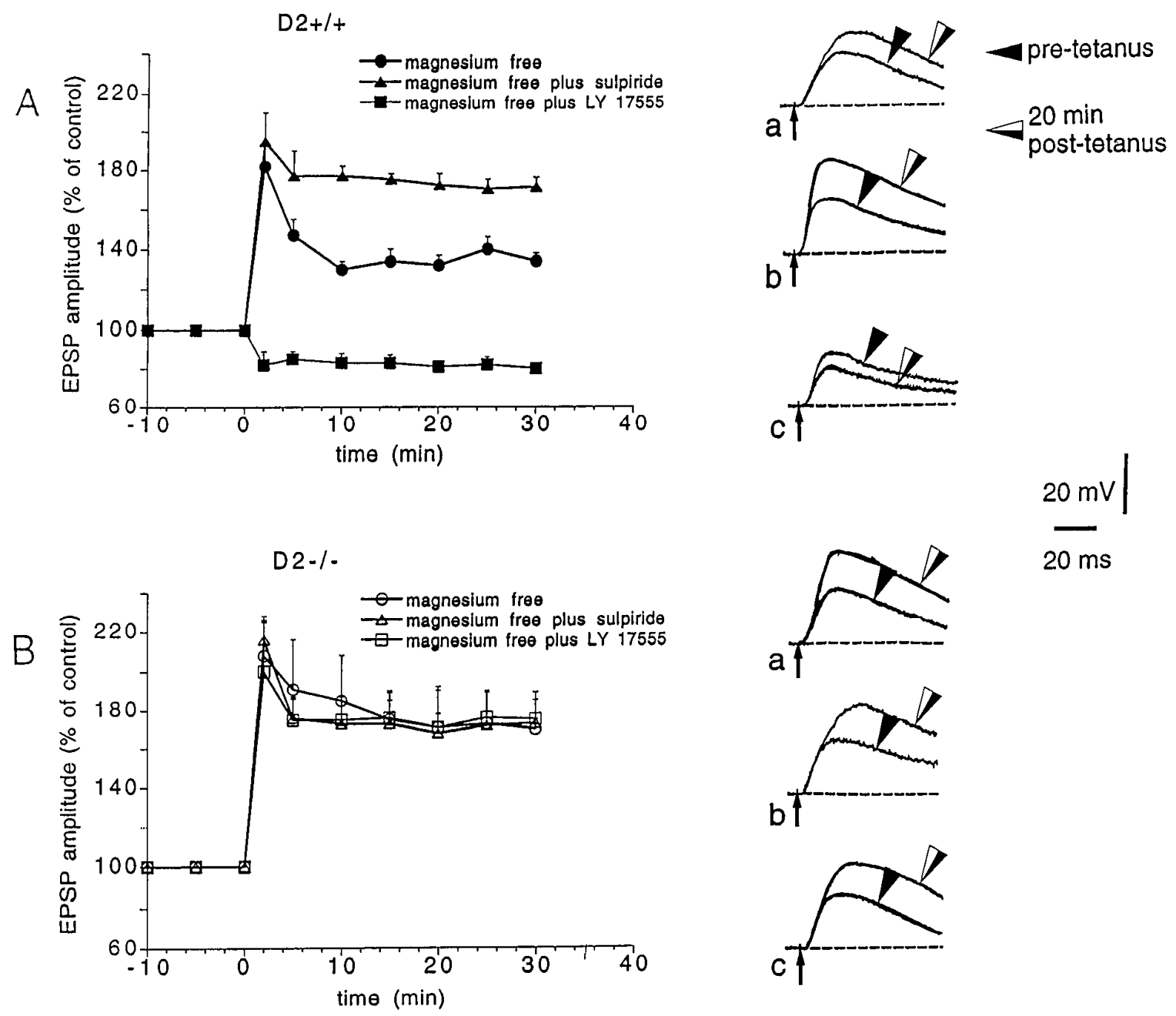

Figure 5. Effects of L-sulpiride and LY 17555 on LTP recorded in magnesium-free medium from WT and D2R-null slices. $A$, The graph shows the long-term effects of tetanic stimulation recorded intracellularly in WT slices in the absence of external magnesium ( filled circles; $n=11$ ), in the absence of magnesium plus $1 \mu \mathrm{M} \mathrm{L}$-sulpiride ( filled triangles; $n=7$ ), and in magnesium-free medium plus $3 \mu \mathrm{M} \mathrm{LY} 17555$ ( filled squares; $n=7$ ). Traces on the right represent EPSP recorded from WT slices in magnesium-free solution $(a)$, in magnesium-free medium plus L-sulpiride $(b)$, and in the absence of magnesium plus LY $17555(c)$. B, The graph shows the LTP recorded in D2R-null slices in the absence of external magnesium (open circles; $n=10)$, in the absence of magnesium plus $1 \mu \mathrm{M} \mathrm{L}$-sulpiride (open triangles; $n=8$ ), and in magnesium-free medium plus $3 \mu \mathrm{M}$ LY 17555 (open squares; $n=9$ ). Traces on the right represent EPSP recorded from D2R-null slices in magnesium-free solution $(a)$, in magnesium-free medium plus L-sulpiride $(b)$, and in the absence of magnesium plus LY 17555 (c). Time and voltage calibrations apply for both $A$ and $B$.

presence of L-sulpiride, thus confirming the modulatory role of D2Rs on the NMDA-dependent LTP. Accordingly, when magnesium was omitted, the LTP observed in D2R-null mice was not affected by either $1 \mu \mathrm{M}$ L-sulpiride (Fig. $5 B)(n=8)$ or $3 \mu \mathrm{M} \mathrm{LY}$ 17555 (Fig. $5 B)(n=9)$.

We have also measured the amplitude, half-decay time, and duration of the membrane depolarizations induced by tetanic stimulation in WT and D2R-null mice in the absence of external magnesium. The amplitude was $43 \pm 4 \mathrm{mV}(n=11)$ in WT animals and $44 \pm 5 \mathrm{mV}(n=10)$ in D2R-null mice $(p>0.05)$. The half-decay time was $3.5 \pm 0.3 \mathrm{sec}(n=11)$ in WT mice and $3.6 \pm 0.4 \sec (n=10)$ in D2R-null animals $(p>0.05)$. The duration was $12.7 \pm 3 \mathrm{sec}(n=11)$ in WT mice and $12.5 \pm 4 \mathrm{sec}$ $(n=10)$ in D2R-null animals $(p>0.05)$.

\section{DISCUSSION}

\section{Main findings}

This study represents the first functional demonstration of a close interaction between D2Rs and glutamate-mediated synaptic plas- ticity in the striatum. We show that in D2R-null mice, highfrequency stimulation of corticostriatal fibers induces an NMDAdependent LTP instead of LTD, as in WT animals. Moreover, we also demonstrate that D2Rs exert a negative control on the LTP observed in WT slices when magnesium is omitted from the external medium (Calabresi et al., 1992a). Indeed, under this condition, in WT slices L-sulpiride enhanced the amplitude of LTP, whereas LY 17555 reversed this phenomenon into LTD. Interestingly, in D2R-null slices the effects of both L-sulpiride and LY 17555 were lost, and the amplitude of LTP in magnesium-free medium was significantly larger than that measured from WT slices in the same experimental condition. These findings strengthen the idea that dopamine plays a crucial function in the formation of striatal LTD. We have shown previously that (1) both D1Rs and D2Rs are required for striatal LTD formation (Calabresi et al., 1992a, 1996a) and (2) endogenous dopamine release is increased immediately after the induction of striatal LTD (Calabresi et al., 1995). The present study, however, suggests 
that D2Rs play a pivotal role in controlling the direction of striatal synaptic plasticity.

D2R-null mice present a parkinsonian-like phenotype (Baik et al., 1995), which is not dictated by changes in the intrinsic membrane properties and synaptic strength of striatal cells; we show that these parameters are unaltered in these mice. This is in agreement with previous studies (Calabresi et al., 1987, 1993a). We suggest that the D2R-null mice phenotype is induced by loss of D2R-mediated control on high-frequency activation of glutamatergic inputs. This loss might cause a profound shift in the direction of long-term excitability at corticostriatal synapses (the appearance of NMDA-dependent LTP instead of LTD).

\section{Possible mechanisms underlying the emergence of LTP in D2R-null mice}

Pre- and postsynaptic mechanisms might be implicated in the generation of LTP in D2R-null mice. Presynaptic D2-like dopamine receptors inhibit the release of glutamate from corticostriatal terminals (Maura et al., 1988). The absence of these inhibitory presynaptic receptors in D2R-null mice might augment the release of glutamate and favor the emergence of LTP instead of LTD. This hypothesis, however, is unlikely, because WT and D2R-null mice had corticostriatal EPSPs of similar amplitude both in normal conditions and in the absence of magnesium. Moreover, the incubation of WT slices either in L-sulpiride or in LY 17555 did not alter the EPSP amplitude, suggesting that, at least in our experimental conditions, D2Rs located on corticostriatal terminals do not play a significant function in the regulation of glutamate release in the striatum.

In WT mice, tetanic stimulation in the presence of L-sulpiride caused only a transient potentiation of excitatory transmission, but not LTP. Thus, acute blockade of D2-like receptors is not sufficient to produce this form of synaptic plasticity. Possibly a long-term antagonism of these receptors or very selective D2R antagonists are required to cause LTP. Alternatively, LTP might result from adaptative changes occurring in D2R-null mice. Postsynaptic changes in glutamate receptor function, such as increased expression of NMDA receptors or abnormal distribution or rearrangement of different subunits, might also occur in D2R-null mice. Dopamine deafferentation enhances the levels of NMDA-sensitive binding in the striatum and increases striatal NMDAR1 subunit mRNA levels (Tremblay et al., 1995). Increased expression of striatal NMDA receptors in Parkinson's disease patients has also been reported (Ulas et al., 1994). In D2R-null mice, however, we did not detect significant differences in the postsynaptic sensitivity to exogenous NMDA or in the NMDA-component of the EPSP evoked by a single stimulus. In contrast, Cepeda et al. (1993) showed that activation of D2-like receptors attenuates NMDA responses in striatum. Although at present there is no explanation for this discrepancy, one possibility could be the different experimental model and conditions used.

If D2R-null mice were to express altered striatal NMDA receptors, we should assume that this abnormality is revealed only in particular conditions, such as high-frequency activation of corticostriatal fibers. We can speculate that under this condition endogenous glutamate selectively activates postsynaptic NMDA receptors on dendritic spines. This location might be particularly important for the postsynaptic cross-talk between D2Rs and NMDA receptors. Nevertheless, similar membrane depolarization characteristics induced by tetanic stimulation (in physiological medium and in absence of external magnesium) were exhibited by WT and D2R-null neurons, making this possibility unlikely. Alternatively, lack of D2Rs might not alter NMDA receptors per se, but it rather affects the physiological events after the activation of glutamate receptors. In fact, postsynaptic D2Rs might exert a negative control on the mechanisms activated by sustained stimulation of NMDA receptors.

Activation of D2Rs inhibits calcium currents in isolated spiny striatal neurons (Surmeier et al., 1996) but also influences inositol-1,4,5-trisphosphate (IP3) production (Clapham, 1995). Interestingly, in pituitary cells, activation of D2Rs inhibits calcium release through the inhibition of IP3 levels (Vallar and Meldolesi, 1989). Because a rise of intracellular calcium concentration is a critical factor in the generation of synaptic plasticity in striatum (Calabresi et al., 1996b) as well as in other brain areas (Malenka et al., 1988; Artola et al., 1996; Neveu and Zucker, 1996), the possible contribution of this D2R-regulated pathway in the formation of striatal NMDA-dependent LTP needs to be investigated further. In addition, activation of D2-like receptors opens potassium channels in a subset of striatal neurons, which might also contribute to the expression of synaptic plasticity in this structure (Greif et al., 1995).

\section{Dopamine in hippocampal synaptic plasticity}

Because the hippocampus and the mesolimbic dopaminergic system have been implicated in the reinforcement of learning and reward mechanisms (Wise, 1996), a growing line of research has been centered on investigation of the role of dopamine in hippocampal synaptic plasticity. Indeed, activation of D1-like receptors enhances LTD of synaptic transmission induced by lowfrequency stimulation in rat hippocampal CA1 neurons (Chen et al., 1995). Similarly, blockade of either D2- or D1-like receptors decreases the magnitude of late phases of LTP, which seems to involve cAMP-dependent mechanisms (Frey et al., 1990, 1991, 1993). Slices perfusion with high concentrations of D1-like agonists without any tetanus can itself mimic the late phases of LTP; this effect is blocked by inhibitors of protein synthesis (Huang and Kandel, 1995). Interestingly, D1R/D5R activation produces a synapse-specific enhancement of early LTP through the increase of intracellular cAMP (Otmakhova and Lisman, 1996). Together these data suggest the involvement of different dopaminedependent mechanisms in the control of synaptic plasticity in various brain areas.

\section{Functional implications}

LTP is regarded as the primary experimental model for investigating the synaptic basis of learning and memory in vertebrates (Bliss and Collingridge, 1993; Malenka, 1994; Nicoll and Malenka, 1995; Artola et al., 1996). The emergence of LTP in striatal neurons in a D2R-deficient background might seem to be a paradox. Nevertheless, striatal spiny neurons are GABAergic cells inhibiting the activity of substantia nigra reticulata and globus pallidus neurons (Alexander and Crutcher, 1990; Graybiel, 1990). Thus, a long-term enhancement of striatal excitability would result in increased inhibitory influence on the basal ganglia activity. In contrast, the striatal LTD observed in physiological conditions has the opposite effect. Interestingly, LTD of synaptic transmission plays a crucial role in the cerebellum, a structure also involved in motor control (Ito, 1989; Linden, 1994; Linden and Connor, 1995). In addition to movement control (Schultz and Romo, 1988; Alexander et al., 1990), the striatum is also involved in motor skills storage (Seitz et al., 1990; Cummings, 1993), learning processes (Whinshaw et al., 1987; McDonald and White, 1994), and reward (Apicella et al., 1991). 
Striatal neurons integrate signals originating from nigral dopaminergic cells and excitatory glutamatergic inputs arising from cortical areas (Kotter, 1994; Starr, 1995). How striatal neurons exert this integrative function is unclear. We provide evidence for a possible cellular substrate for this interaction. Imbalance in the function of D2Rs and NMDA glutamate receptors within the striatum could play a major role in the pathophysiology of Parkinson's disease and schizophrenia (Carlsson and Carlsson, 1990; Starr, 1995). Indeed, D2R antagonists induce parkinsonian symptoms, whereas NMDA receptor antagonists improve Parkinson's disease therapy (Starr, 1995). Interestingly, dopamine and NMDA receptor antagonists favor the emergence of LTD versus LTP in the rat prefrontal cortex (Law-Tho et al., 1995). Although the pharmacology of the dopamine receptors involved in this modulatory action has not been characterized, we hypothesize, as demonstrated by the present study in the striatum, a possible regulatory function of D2Rs on synaptic plasticity expressed in cortical areas. This possibility might have profound implications in the pathophysiology of schizophrenia, a mental disease in which an altered balance between D2Rs and NMDA receptors in cortical and subcortical activity has been postulated (Carlsson and Carlsson, 1990; Seeman, 1993; Lingjaerde, 1994).

\section{REFERENCES}

Albin RL, Young AB, Penney JB (1989) The functional anatomy of basal ganglia disorders. Trends Neurosci 12:366-375.

Alexander GE, Crutcher MD (1990) Functional architecture of basal ganglia circuits: neural substrates of parallel processing. Trends Neurosci 13:266-271.

Alexander GE, Crutcher MD, DeLong MR (1990) Basal gangliathalamocortical circuits: parallel substrates for motor, oculomotor, prefrontal and limbic functions. Prog Brain Res 85:119-146.

Apicella P, Ljungberg T, Scarnati E, Schultz W (1991) Responses to reward in monkey dorsal and ventral striatum. Exp Brain Res 85:491-500.

Artola A, Hensch T, Singer W (1996) Calcium-induced long-term depression in the visual cortex of the rat in vitro. J Neurophysiol 76:984-994.

Baik J-H, Picetti R, Saiardi A, Thiriet G, Dierich A, Depaulis A, Le Meur M, Borrelli E (1995) Parkinsonian-like locomotor impairment in mice lacking dopamine D2 receptors. Nature 377:424-428.

Bliss TVP, Collingridge GL (1993) A synaptic model of memory: longterm potentiation in the hippocampus. Nature 361:31-39.

Calabresi P, Mercuri NB, Stanzione P, Stefani A, Bernardi G (1987) Intracellular studies on the dopamine-induced firing inhibition of neostriatal neurons in vitro: evidence for D1 receptor involvement. Neuroscience 20:757-771.

Calabresi P, Mercuri NB, Bernardi G (1990) Synaptic and intrinsic control of membrane excitability of neostriatal neurons. II. An in vitro analysis. J Neurophysiol 63:663-675.

Calabresi P, Maj R, Pisani A, Mercuri NB, Bernardi G (1992a) Longterm synaptic depression in the striatum: physiological and pharmacological characterization. J Neurosci 12:4224-4233.

Calabresi P, Pisani A, Mercuri NB, Bernardi G (1992b) Long-term potentiation in the striatum is unmasked by removing the voltagedependent blockade of NMDA receptor channel. Eur J Neurosci 4:929-935.

Calabresi P, Mercuri NB, Sancesario G, Bernardi G (1993a) Electrophysiology of dopamine-denervated striatal neurons: implications for Parkinson's disease. Brain 116:433-452.

Calabresi P, Pisani A, Mercuri NB, Bernardi G (1993b) Lithium treatment blocks long-term synaptic depression in the striatum. Neuron 10:955-962.

Calabresi P, Pisani A, Mercuri NB, Bernardi G (1994) Post-receptor mechanisms underlying striatal long-term depression. J Neurosci 14:4871-4881.

Calabresi P, Fedele E, Pisani A, Fontana G, Mercuri NB, Bernardi G, Raiteri M (1995) Transmitter release associated with long-term synaptic depression in rat corticostriatal slices. Eur J Neurosci 7:1889-1894.

Calabresi P, Pisani A, Mercuri NB, Bernardi G (1996a) The corticostria- tal projection: from synaptic plasticity to basal ganglia disorders. Trends Neurosci 19:19-24.

Calabresi P, Pisani A, Centonze D, Bernardi G (1996b) Role of $\mathrm{Ca}^{2+}$ in striatal LTD and LTP. Semin Neurosci 8:321-328.

Carlsson M, Carlsson A (1990) Interaction between glutamatergic and monoaminergic system within the basal ganglia: implication for schizophrenia and Parkinson's disease. Trends Neurosci 13:272-276.

Cepeda C, Buchwald NA, Levine MS (1993) Neuromodulatory actions of dopamine in the neostriatum are dependent upon the excitatory amino acid receptor subtypes activated. Proc Natl Acad Sci USA 90:9576-9580.

Chen Z, Fujii S, Ito K-I, Kato H, Kaneko K, Miyakawa H (1995) Activation of dopamine D1 receptors enhances long-term depression of synaptic transmission induced by low frequency stimulation in rat hippocampal CA1 neurons. Neurosci Lett 188:195-198.

Cherubini E, Herrling PL, Lanfumey L, Stanzione P (1988) Excitatory amino acids in synaptic excitation of striatal neurones in vitro. J Physiol (Lond) 400:677-690.

Clapham DE (1995) Calcium signaling. Cell 80:259-268.

Cummings JL (1993) Frontal-subcortical circuits and human behavior. Arch Neurol 50:873-880.

Drago J, Gerfen CR, Lachowicz JE, Steiner H, Hollon TR, Love PE, Ooi GT, Grinberg A, Lee EJ, Huang SP, Bartlett PF, Jose PA, Sibley DR, Westphal H (1994) Altered striatal function in a mutant mouse lacking D1A dopamine receptors. Proc Natl Acad Sci USA 91:12564-12568.

Frey U, Schroeder H, Matthies H (1990) Dopaminergic antagonists prevent long-term maintenance of posttetanic LTP in the CA1 region of rat hippocampal slices. Brain Res 522:69-75.

Frey U, Matthies H, Reymann KG (1991) The effect of dopaminergic D1 receptor blockade during tetanization on the expression of long-term potentiation in the CA 1 region in vitro. Neurosci Lett 129:111-114.

Frey U, Huang Y-Y, Kandel ER (1993) Effects of cAMP simulate a late stage of LTP in hippocampal CA1 neurons. Science 260:1661-1664.

Gingrich JA, Caron MG (1993) Recent advances in the molecular biology of dopamine receptors. Annu Rev Neurosci 16:299-321.

Graybiel AM (1990) Neurotransmitters and neuromodulators in the basal ganglia. Trends Neurosci 13:244-253.

Greif JG, Lin Y-J, Liu J-C, Freedman JE (1995) Dopamine-modulated potassium channels on rat striatal neurons: specific activation and cellular expression. J Neurosci 15:4533-4544.

Huang Y-Y, Kandel ER (1995) D1/D5 receptor agonists induce a protein synthesis-dependent late potentiation in the CA1 region of the hippocampus. Proc Natl Acad Sci USA 92:2446-2450.

Ito M (1989) Long-term depression. Annu Rev Neurosci 12:85-102.

Jiang ZG, North RA (1991) Membrane properties and synaptic responses of rat striatal neurones in vitro. J Physiol (Lond) 443:533-553.

Kita T, Kita K, Kitai ST (1984) Passive electrical membrane properties of rat neostriatal neurons in an in vitro slice preparation. Brain Res 300:129-139.

Kotter R (1994) Postsynaptic integration of glutamatergic and dopaminergic signals in the striatum. Prog Neurobiol 44:163-196.

Law-Tho D, Desce JM, Crepel F (1995) Dopamine favours the emergence of long-term depression versus long-term potentiation in slices of rat prefrontal cortex. Neurosci Lett 188:125-128.

Linden DJ (1994) Long-term synaptic depression in the mammalian brain. Neuron 12:457-472.

Linden DJ, Connor JA (1995) Long-term synaptic depression. Annu Rev Neurosci 18:319-357.

Lingjaerde O (1994) New perspectives on biological treatment of schizophrenia. Acta Psychiatr Scand 90[Suppl 384]:102-107.

Lovinger DM, Tyler EC, Merrit A (1993) Short- and long-term synaptic depression in the neostriatum. J Neurophysiol 70:1937-1949.

Malenka RC (1994) Synaptic plasticity in the hippocampus: LTP and LTD. Cell 78:535-538.

Malenka RC, Kauer JC, Zucker RS, Nicoll RA (1988) Postsynaptic calcium is sufficient for potentiation of hippocampal synaptic transmission. Science 242:81-84.

Maura G, Giardi A, Raiteri M (1988) Release-regulating D2 dopamine receptors are located on striatal glutamatergic nerve terminals. J Pharmacol Exp Ther 247:680-684.

McDonald RJ, White NM (1994) Parallel information processing in water maze: evidence for independent memory systems involving dorsal striatum and hippocampus. Behav Neural Biol 61:260-270.

Mulkey RM, Malenka RC (1992) Mechanisms underlying induction of 
homosynaptic long-term depression in area CA1 of the hippocampus. Neuron 9:967-975.

Neveu D, Zucker RS (1996) Postsynaptic levels of $\left[\mathrm{Ca}^{2+}\right]_{i}$ needed to trigger LTD and LTP. Neuron 16:619-629.

Nicoll RA, Malenka RC (1995) Contrasting properties of two forms of synaptic potentiation in the hippocampus. Nature 377:115-118.

Nicoll RA, Malenka RC (1995) Contrasting properties of two forms of synaptic potentiation in the hippocampus. Nature 377:115-118.

Otmakhova NA, Lismon JE (1996) D1/D5 dopamine receptor activation increases the magnitude of early long-term potentiation at CA1 hippocampal synapses. J Neurosci 16:7478-7486.

Seasack SR, Aoki C, Pickel VM (1994) Ultrastructural localization of D2 receptor-like immunoreactivity in midbrain dopamine neurons and their striatal targets. J Neurosci 14:88-106.

Seeman P (1993) Schizophrenia as a brain disease. Arch Neurol 50:1093-1095.

Seitz RJ, Roland PE, Bohm C, Greitz T, Stone-Elander S (1990) Motor learning in man: a positron emission tomographic study. NeuroReport 1:17-20.

Smith AD, Bolam JP (1990) The neuronal network of the basal ganglia as revealed by the study of synaptic connections of identified neurones. Trends Neurosci 13:259-265.

Starr MS (1995) Glutamate-dopamine D1/D2 balance in basal ganglia and its relevance to Parkinson's disease. Synapse 19:264-293.

Surmeier DJ, Song W-J, Zhen Y (1996) Coordinated expression of do- pamine receptors in neostriatal medium spiny neurons. J Neurosci 15:6579-6591.

Tremblay M, Salin P, Soghomonian J-J (1995) Effect of 6-OHDA lesions on striatal mRNA levels encoding for glutamate receptor subunits. NeuroReport 6:2225-2229.

Ulas J, Weihmuller FB, Brunner LC, Joyce JN, Marshall JF, Cotman CW (1994) Selective increase of NMDA-sensitive glutamate binding in the striatum of Parkinson's disease, Alzheimer's disease, and mixed Parkinson's disease/Alzheimer's disease patients: an autoradiographic study. J Neurosci 14:6317-6324.

Vallar L, Meldolesi J (1989) Mechanisms of signal transduction at the dopamine D2 receptors. Trends Pharmacol Sci 10:74-77.

Walsh JP (1993) Depression of excitatory input in rat striatal neurons. Brain Res 608:123-128.

Whinshaw IQ, Mittelman G, Bunch ST, Dunnett SB (1987) Impairments in the acquisition, retention and selection of spatial navigation strategies after medial caudate-putamen lesions in rats. Behav Brain Res 24:125-138.

Wise RA (1996) Addictive drugs and brain stimulation reward. Annu Rev Neurosci 19:319-340.

Xu M, Moratalla R, Gold LH, Hiroi N, Koob GF, Graybiel AM, Tonegawa S (1994) Dopamine D1 receptor mutant mice are deficient in striatal expression of dynorphin and in dopamine-mediated behavioral responses. Cell 79:729-742. 